\title{
Long-term exposure to gaseous air pollutants and cardio-respiratory mortality in Brisbane, Australia
}

\author{
Xiao Yu Wang ${ }^{1}$, Wenbiao $\mathrm{Hu}^{2}$, Shilu Tong ${ }^{1}$ \\ ${ }^{1}$ School of Public Health and Institute of Health and Biomedical Innovation, Queensland University of \\ Technology, Kelvin Grove, Qld. 4059, Australia; ${ }^{2}$ School of Population Health, University of Queensland, \\ Herston Road, Herston, Qld 4029, Australia
}

\begin{abstract}
This study examines the association of long-term exposure to gaseous air pollution with cardio-respiratory mortality in Brisbane, Australia, in the period 1996-2004. The pollutant concentrations were estimated using geographical information system (GIS) techniques at the statistical local area (SLA) level. The generalized estimating equations model was used to investigate the impact of nitrogen dioxide $\left(\mathrm{NO}_{2}\right)$, ozone $\left(\mathrm{O}_{3}\right)$ and sulphur dioxide $\left(\mathrm{SO}_{2}\right)$ on mortality due to cardio-respiratory disease after adjusting for a range of potential confounders. An increase of $4.7 \%$ $(95 \%$ confidence interval $=0.7-8.9 \%)$ in cardio-respiratory mortality for 1 part per billion $(\mathrm{ppb})$ increment in annual average concentration of $\mathrm{SO}_{2}$ was estimated. However, there was no significant association between long-term exposures to $\mathrm{NO}_{2}$ or $\mathrm{O}_{3}$ and death due to cardio-respiratory disease. The results indicate that the annual average concentration of $\mathrm{SO}_{2}$ is associated with cardio-respiratory mortality at the SLA level and this association appears to vary with the geographical area.
\end{abstract}

Keywords: cardio-respiratory mortality, air pollution, nitrogen dioxide, ozone, sulphur dioxide, spatial analysis, Australia.

\section{Introduction}

Air pollution is ranked by the World Health Organization (WHO) as one of the top ten contributors to the global burden of disease and injury. Exposure to gaseous air pollutants, even at a low level, has been associated with cardio-respiratory diseases (Vedal et al., 2003). Most recent epidemiological studies of air pollution have used time-series analyses to explore the relationship between daily mortality or morbidity and daily ambient air pollution concentrations based on the same day or previous days (Hajat et al., 2007).

Corresponding author:

Shilu Tong

School of Public Health and Institute of Health and

Biomedical Innovation

Queensland University of Technology

Kelvin Grove, Qld. 4059, Australia

Tel. +61 73138 9745; Fax +61 731383369

E-mail: s.tong@qut.edu.au
However, most of the previous studies have examined the association between air pollution and health outcomes using air pollution data from a single monitoring site, or average values from a few monitoring sites, to represent the whole population of the study area. In fact, for a metropolitan city, ambient air pollution levels may differ significantly among different areas and there is increasing concern that the relationships between air pollution and mortality may vary with geographical area (Chen et al., 2007). Additionally, some studies have indicated that socio-economic status can act as a confounding factor when investigating the relation between geographical location and health (Scoggins et al., 2004).

This study examines the spatial variation in the relationship between long-term exposure to gaseous air pollutants - including nitrogen dioxide $\left(\mathrm{NO}_{2}\right)$, ozone $\left(\mathrm{O}_{3}\right)$ and sulphur dioxide $\left(\mathrm{SO}_{2}\right)$ - and cardiorespiratory mortality in Brisbane, Australia, during the period 1996-2004. 


\section{Materials and methods}

\section{Study area}

Brisbane is the capital of Queensland and the third largest city after Sydney and Melbourne in Australia. Its urban areas cover $1326.8 \mathrm{~km}^{2}$ and the population has increased by $16.3 \%$ from 824,489 in mid-1996 to 958,504 in mid-2004. In this study, the data analysis was undertaken at the statistical local area (SLA) level, i.e. the basic spatial unit used to collect and analyse data. There were 162 SLAs in Brisbane during the study period.

\section{Gaseous air pollutants}

Daily data on maximum 1-hour $\mathrm{O}_{3}, \mathrm{NO}_{2}$ and $\mathrm{SO}_{2}$ concentrations in parts per billion (ppb), recorded in 13 monitoring stations for the period of 1 January 1996 to 31 December 2004, were obtained from the Queensland Environmental Protection Agency (QEPA) (Fig. 1). The daily $\mathrm{O}_{3}, \mathrm{NO}_{2}$ and $\mathrm{SO}_{2}$ concentrations were aggregated to annual means and used as long-term gaseous air pollution exposure indicators. Geographical information system (GIS) techniques were used for mapping the spatial patterns of annual average $\mathrm{O}_{3}, \mathrm{NO}_{2}$ and $\mathrm{SO}_{2}$ concentrations at the SLA level.

\section{Health data}

In order to assess the association between exposure to gaseous air pollutants and cardio-pulmonary mortality at the SLA level, we estimated the annual average potential concentrations of gaseous pollutants by SLA using an inverse distance weighted (IDW) method (O'Sullivan and Unwin, 2003), as most SLAs did not have a monitoring station.

Mortality data were provided by the Office of Economic and Statistical Research of the Queensland Treasury. Apart from date and cause of death, the data used included sex, age and SLA of residence. The cause-specific mortality were categorised according to the International Classification of Diseases version 9 (ICD-9 code) or version 10 (ICD-10 code) and were defined as cardio-respirato-

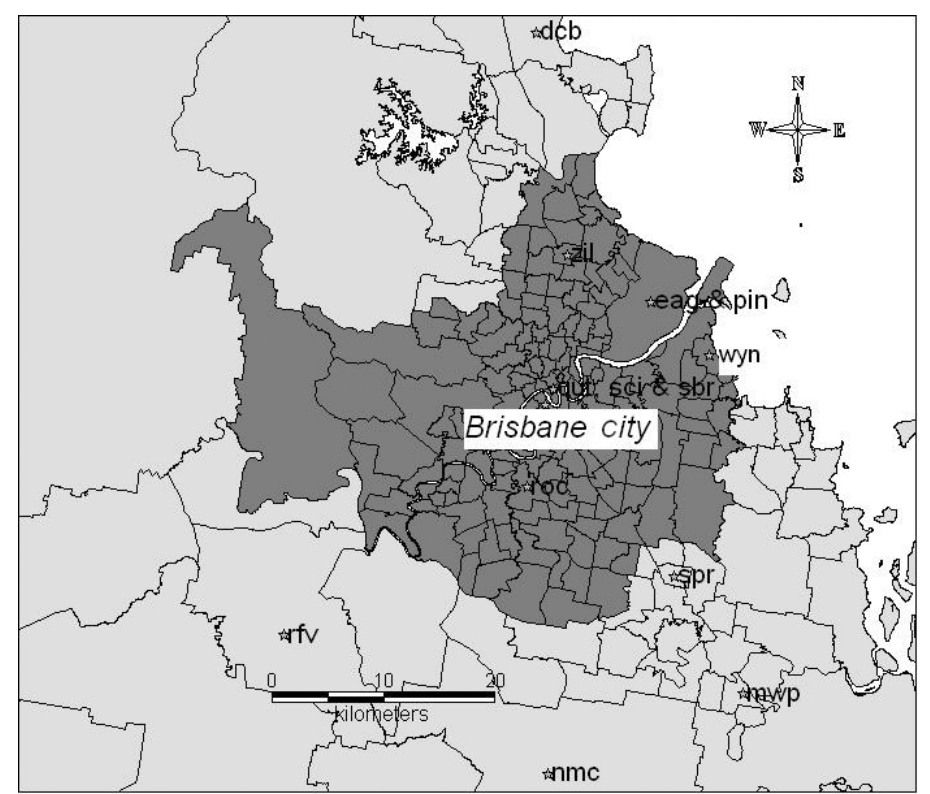

Fig. 1. Locations of air pollution monitoring stations around urban Brisbane city (13 monitoring stations in total: Brisbane CBD (qut), Brisbane CBD (sci), Deception Bay (dcb), Eagle Farm (eag), Flinders View (rfv), Mount Warren Park (mwp), North Maclean (nmc), Pinkenba (pin), Rocklea (roc), South Brisbane (sbr), Springwood (spr), Wynnum (wyn) and Zillmere (zil)). 
ry diseases (CRD) (ICD 9: 390-519; ICD 10: I00I99 and J00-J99), including both respiratory and cardio-vascular diseases (Vedal et al., 2003; Scoggins et al., 2004). During the study period, 51,233 deaths were recorded, including 27,480 cardio-respiratory deaths. To compare the spatial patterns of cardio-respiratory mortality across SLAs, an indirect method (i.e. using the Brisbane population as a reference) was used to calculate the agestandardized mortality rate (ASM) for each SLA, adjusted for differences in the age and sex distributions among SLAs (Selvin, 2001).

The 2001 census provided information on resident population, sex, and age groups by SLA for Brisbane city. We also obtained the socio-economic indexes for areas (SEIFA) and data for each SLA in 2001 from the Australian Bureau of Statistics.

\section{Statistical analysis}

The generalised estimating equations (GEE) model was used to investigate how gaseous air pollutants influence the probability of deaths as this model is capable of removing spatial autocorrelation of residuals and can implement unbiased regression in spatial analysis (Hedeker and Ebooks, 2006; Carl and Kühn, 2007). We controlled for confounding effects of age
$(<14,15-64,65-74$ and $75+$ years $)$, sex, calendar year, the SEIFA disadvantage index, and the population size using an offset term in the model. The dependent variable was the annual counts of cardio-respiratory deaths for each SLA, while the annual means of gaseous air pollutants constituted independent variables. Both single pollutant and multiple pollutants models were performed in relation to cardio-respiratory mortality using the SAS statistical software package. Finally, Moran's I statistic, with a contiguitybased spatial weights matrix, was calculated to assess spatial autocorrelation of residuals using ArcGIS 9.2.

\section{Results}

The daily maximum 1-h $\mathrm{NO}_{2}, \mathrm{O}_{3}$ and $\mathrm{SO}_{2}$ concentrations recorded in Brisbane are presented in Table 1. The overall averages of these gases were $19.8 \mathrm{ppb}, 30.1 \mathrm{ppb}$ and $5.4 \mathrm{ppb}$, respectively.

Pearson correlations between gaseous pollutants were calculated in three different types of monitoring stations: Eagle Farm (light industrial area), Brisbane CBD (qut) (commercial area) and Springwood (residential area) as they all have longterm monitoring data (Table 1). The correlations between $\mathrm{NO}_{2}, \mathrm{O}_{3}$ and $\mathrm{SO}_{2}$ concentrations in each station ranged from 0.10 to 0.48 . For the same

Table 1. Summary statistics of gaseous air pollutants in all monitoring stations, Brisbane, Australia (1996-2004).

\begin{tabular}{|c|c|c|c|c|c|c|c|}
\hline \multirow[b]{2}{*}{ Monitoring site } & \multirow[b]{2}{*}{ Area classification } & \multicolumn{2}{|c|}{$\operatorname{Max} 1-\mathrm{h} \mathrm{NO}_{2}$} & \multicolumn{2}{|c|}{$\operatorname{Max} 1-\mathrm{h} \mathrm{O}_{3}$} & \multicolumn{2}{|c|}{$\operatorname{Max} 1-\mathrm{h} \mathrm{SO}$} \\
\hline & & Mean & $\mathrm{SD}^{\mathrm{a}}$ & Mean & $\mathrm{SD}^{\mathrm{a}}$ & Mean & $\mathrm{SD}^{\mathrm{a}}$ \\
\hline Brisbane CBD (qut) & Commercial & 21.7 & 8.8 & 28.2 & 13.5 & 4.9 & 3.9 \\
\hline Brisbane CBD (sci) & Commercial & 25.4 & 10.4 & 23.7 & 7.9 & 3.2 & 2.4 \\
\hline Deception Bay (dcb) & Residential & 16.8 & 8.6 & 32.1 & 9.9 & - & - \\
\hline Eagle Farm (eag) & Light industrial & 21.6 & 9.7 & 29.9 & 10.8 & 6.4 & 5.4 \\
\hline Flinders View (rfv) & Residential & 19.8 & 8.1 & 35.6 & 13.8 & 7.7 & 8.7 \\
\hline Mount Warren Park (mwp) & Residential & 15.1 & 8.1 & 32.1 & 12.4 & - & - \\
\hline North Maclean (nmc) & Rural & 11.0 & 5.8 & 35.0 & 13.9 & - & - \\
\hline Pinkenba (pin) & Residential (adjacent to industry and airport) & 18.9 & 6.6 & 29.9 & 8.7 & 7.8 & 7.8 \\
\hline Rocklea (roc) & Residential/light industrial & 20.1 & 9.1 & 34.3 & 13.5 & - & - \\
\hline South Brisbane (sbr) & Commercial & 28.0 & 9.0 & - & - & - & - \\
\hline Springwood (spr) & Residential & 19.4 & 7.7 & 27.0 & 8.7 & 2.5 & 2.8 \\
\hline Wynnum (wyn) & Residential (adjacent to industrial zone) & 20.8 & 10.1 & 25.8 & 7.6 & 5.1 & 5.4 \\
\hline Zillmere (zil) & Light industrial area & 18.8 & 8.3 & 27.1 & 11.3 & - & - \\
\hline
\end{tabular}

aSD = standard deviation; - = not recorded. 

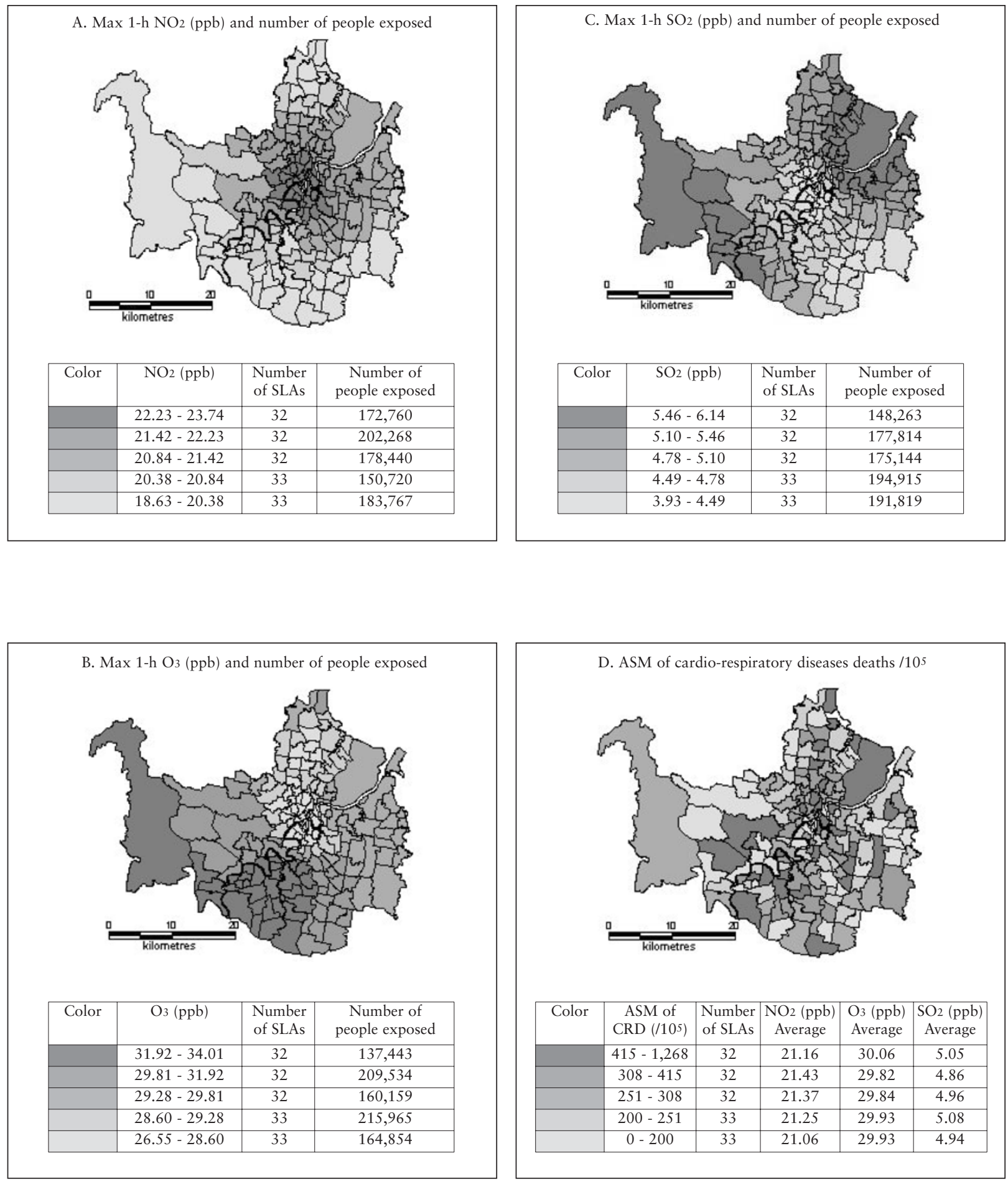

Fig. 2. Spatial patterns of annual average concentrations of $\mathrm{NO}_{2}, \mathrm{O}_{3}$ and $\mathrm{SO}_{2}$; annual average ASM of cardio-respiratory mortality in Brisbane, Australia (1996-2004). 
gaseous air pollutant across different monitoring stations, there were moderate to high correlations for $\mathrm{NO}_{2}$ concentrations (ranging from 0.35 to 0.89 ), and $\mathrm{O}_{3}$ concentrations (ranging from 0.33 to 0.89 ), but only moderate correlations for $\mathrm{SO}_{2}$ concentrations (ranging from -0.22 to 0.53 ).

Figure 2 shows the spatial patterns of annual average concentrations of gaseous air pollutants $\left(\mathrm{NO}_{2}, \mathrm{O}_{3}\right.$ and $\mathrm{SO}_{2}$ ) and the annual ASM of cardio-respiratory mortality. The number of people exposed is shown for each of the gaseous pollutants, and the average of the gaseous pollutants is also shown in each category of cardio-respiratory mortality at the SLA level.

The highest values of $\mathrm{NO}_{2}$ were recorded around the centre of Brisbane (Fig. 2A). The spatial pattern of $\mathrm{O}_{3}$ appears opposite to the $\mathrm{NO}_{2}$ plot, although with a different dynamical range (Fig. 2B). A negative correlation was found $(\mathrm{r}=-0.69 ; \mathrm{P}<0.01)$ between $\mathrm{O}_{3}$ and $\mathrm{NO}_{2}$. The highest $\mathrm{O}_{3}$ levels were recorded around the Rocklea station which is surrounded by light industry and residential areas. The spatial features of $\mathrm{SO}_{2}$ appeared to differ from those of $\mathrm{NO}_{2}$ and $\mathrm{O}_{3}$ (Fig. 2C). A negative correlation was also found $(\mathrm{r}=-0.29 ; \mathrm{P}<0.01)$ between $\mathrm{NO}_{2}$ and $\mathrm{SO}_{2}$. The highest $\mathrm{SO}_{2}$ levels were observed around the Pinkenba and Eagle Farm stations, which are located in a light to moderately developed industrial area.

There was a strong spatial pattern of cardio-respiratory mortality across SLAs (Fig. 2D). The average ASM of CRD was 321.2 per 100,000 person-years

Table 2. Relative risk for cardio-respiratory mortality from long-term exposure to gaseous air pollutants.

\begin{tabular}{lcc}
\hline \multirow{2}{*}{ Pollutant } & \multicolumn{2}{c}{ Relative risk } \\
\cline { 2 - 3 } & $\begin{array}{c}\text { Single pollutant } \\
(95 \% \mathrm{CI})^{\mathrm{a}}\end{array}$ & $\begin{array}{c}\text { Multiple pollutant } \\
(95 \% \mathrm{CI})^{\mathrm{b}}\end{array}$ \\
\hline $\mathrm{NO}_{2}$ & $0.995(0.970-1.020)$ & $0.997(0.971-1.022)$ \\
$\mathrm{O}_{3}$ & $1.002(0.989-1.015)$ & $0.999(0.986-1.012)$ \\
$\mathrm{SO}_{2}$ & $1.047(1.006-1.090)$ & $1.047(1.007-1.089)$ \\
\hline
\end{tabular}

adjusted for the confounding effects of age, sex, population size, calendar year and SEIFA

bAdjusted for the confounding effects of age, sex, population size, calendar year, SEIFA and other gaseous air pollutants. and the highest ASM of CRD (i.e. 1256 per 100,000 person-years) was found in Sandgate during the study period. Sandgate, with $11 \%$ of the population aged over 75 years, is one of the oldest suburbs in Brisbane and situated on the coastline, along Moreton Bay. The lowest ASM of CRD (0 per 100,000 person-years) was found in three SLAs, i.e. Gumdale, Riverhills and Tingapla. Less than $4 \%$ of the population is aged over 75 years in these areas.

The results of single pollutant and multiple pollutants models were similar and indicated that there was a positive relationship between the annual average $\mathrm{SO}_{2}$ and cardio-respiratory mortality. After controlling for potential confounding factors (i.e. age, sex, population size, calendar year, spatial auto-correlation, SEIFA and other gaseous air pollutants), a $4.7 \%(95 \%$ confidence interval $(\mathrm{CI})=0.7-8.9 \%)$ increase in cardio-respiratory mortality per $1 \mathrm{ppb}$ increase in the annual average $\mathrm{SO}_{2}$ concentrations was estimated. However, there was no significant association of the annual average concentrations of $\mathrm{NO}_{2}$ or $\mathrm{O}_{3}$ with cardio-respiratory mortality (Table 2 ). The residual analyses indicated that there was no significant spatial autocorrelation of residuals for either of the single pollutant (Moran's $I=0.079, \mathrm{P}$ $>0.05$ ) and multiple pollutant model (Moran's $I=$ $0.075, \mathrm{P}>0.05)$. This outcome suggests that the model provided a reasonable fit to the data.

\section{Discussion}

This study found a positive association between long-term exposure to $\mathrm{SO}_{2}$ and cardio-respiratory mortality at the SLA level in the town of Brisbane, on the east coast of Australia. This significant association remained even after simultaneously adjusting for confounding effects such as age, sex, calendar year, SEIFA, population size and other gaseous air pollutants. However, there was no significant association of annual average concentrations of $\mathrm{NO}_{2}$ or $\mathrm{O}_{3}$ with cardio-respiratory mortality.

In the study, we assumed that annual average concentrations of $\mathrm{O}_{3}, \mathrm{NO}_{2}$ and $\mathrm{SO}_{2}$ are appropriate indicators of long-term exposure to air pollution. As 
gaseous pollutants often share the same source, or are subject to the same environmental influences, levels tend to be highly correlated over time. A number of other studies have used a similar approach to estimating long-term exposure to ambient air pollution levels (Vedal et al., 2003; Scoggins et al., 2004). In order to simulate the urban air quality of Brisbane at the uint of the SLA, the IDW method was used to estimate the gaseous air pollutant concentrations of $\mathrm{O}_{3}, \mathrm{NO}_{2}$ and $\mathrm{SO}_{2}$ for each SLA (O'Sullivan and Unwin, 2003). This method provides a more complete spatial picture of air quality than monitoring data which is only available from a few stations. This is necessary for examining the effects of long-term exposure to air pollution because no single site can represent air quality of a whole city.

Exposure to air pollution affects mortality and the number of hospital admissions. However, relatively few studies have addressed the long-term effects of air pollution on mortality, and most of them have shown an association for $\mathrm{NO}_{2}$ (Scoggins et al., 2004) and particulate matter (Pope et al., 2002). The levels of air pollution in Brisbane were found to be lower than most metropolitan cities in the world. The results of this spatial analysis still show a statistically significant association between the annual mean of $\mathrm{SO}_{2}$ and cardio-respiratory mortality, even after controlling for potential confounding factors at the SLA level. However, we did not find significant effects of long-term exposure to $\mathrm{NO}_{2}$ and $\mathrm{O}_{3}$ on cardio-respiratory mortality.

In our opinion, the current study has three major strengths. Firstly, it systematically examined the spatial distribution of cardio-respiratory mortality associated with long-term exposure to gaseous air pollution in a metropolitan setting. Secondly, most of the known confounding factors have been controlled for, including age, sex, population size, calendar year, spatial auto-correlation and SEIFA at the SLA level. Finally, the inclusion of SEIFA as a composite index of socio-economic status also reflects the influence of some unmeasured factors such as smoking habits and physical inactivity spelled out in the report on "Chronic Conditions and Health Risk Factors" published by the South Australian Department of Health.

Limitations are also encountered in this study. Firstly, seasonal differences in air pollution and mortality patterns were not examined as we only used annual average of data. Secondly, as this is an ecological study, exposure misclassification bias is inevitable to some extent. For example, exposure at people's homes and the place where they work may differ. However, most of the deaths occurred in the elderly who were likely to stay at home most of the time. Hence, the extent of misclassification bias is regarded as limited.

In conclusion, this study used a geospatial approach to analyse the relationship between longterm exposure to gaseous air pollutants and cardiorespiratory mortality. The results of our study indicate that long-term exposure to $\mathrm{SO}_{2}$ in Brisbane, even at the levels lower than most other metropolitan cities, is associated with cardio-respiratory mortality. Furthermore, this association appears to vary with geographic area. Therefore, the spatial features of air pollution and health outcomes should be considered when modelling air pollution and health relationships, particularly for large cities.

\section{Acknowledgements}

This study was partly funded by the Australian Research Council (DP0559655). S. Tong is supported by an NHMRC research fellowship. We thank the Queensland Environmental Protection Agency, the Office of Economic and Statistical Research of the Queensland Treasury and the Australian Bureau of Statistics for providing the data for this study.

\section{References}

Carl G, Kühn I, 2007. Analyzing spatial autocorrelation in species distributions using Gaussian and logit models. Ecol Model 207, 159-170.

Chen L, Mengersen K, Tong S, 2007. Spatiotemporal relationship between particle air pollution and respiratory 
emergency hospital admissions in Brisbane, Australia. Sci Total Environ 373, 57-67.

Hajat S, Armstrong B, Wilkinson P, Busby A, Dolk H, 2007. Outdoor air pollution and infant mortality: analysis of daily time-series data in 10 English cities. J Epidemiol Community Health 61, 719-722.

Hedeker D, Ebooks C, 2006. Longitudinal Data Analysis. John Wiley \& Sons, Inc. Hoboken, New Jersey, USA.

O'Sullivan D, Unwin D, 2003. Geographic Information Analysis. John Wiley \& Sons, Inc. Hoboken, New Jersey, USA.

Pope CA 3rd, Burnett RT, Thun MJ, Calle EE, Krewski D, Ito K, Thurston GD, 2002. Lung cancer, cardiopulmonary mortality, and long-term exposure to fine particulate air pollution. JAMA 287, 1132-1141.

Scoggins A, Kjellstrom T, Fisher G, Connor J, Gimsond N, 2004. Spatial analysis of annual air pollution exposure and mortality. Sci Total Environ 321, 71-85.

Selvin S, 2001. Epidemiologic Analysis: A Case-Oriented Approach. New York, Oxford University Press, USA.

South Australian Department of Health 2005. SEIFA (IRSD) - Chronic Conditions and Health Risk Factors. http://www.health.sa.gov.au/pros/portals/0/BR\%202005$28 \% 20$ SEIFA $\% 20$ IRSD $\% 20$ chronic $\% 20$ conditions $\% 20$ an d\%20risk\%20factors.pdf

Vedal S, Brauer M, White R, Petkau J, 2003. Air pollution and daily mortality in a city with low levels of pollution. Environ Health Perspect 111, 45-52. 